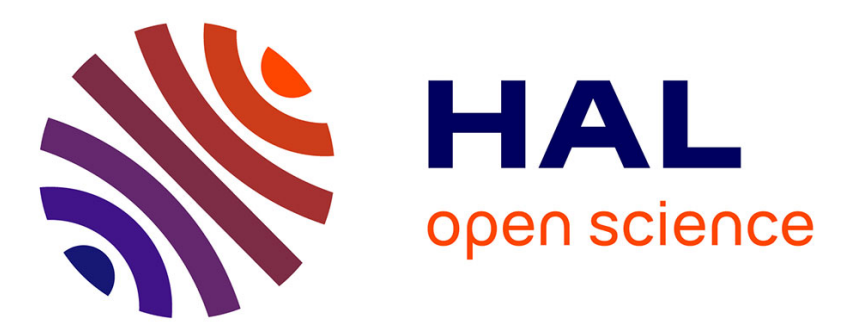

\title{
Lipid phosphate phosphatases form homo- and hetero-oligomers: catalytic competency, sub-cellular distribution and function
}

Jaclyn S Long, Nigel J Pyne, Susan Pyne

\section{- To cite this version:}

Jaclyn S Long, Nigel J Pyne, Susan Pyne. Lipid phosphate phosphatases form homo- and heterooligomers: catalytic competency, sub-cellular distribution and function. Biochemical Journal, 2008, 411 (2), pp.371-377. 10.1042/BJ20071607 . hal-00478925

\section{HAL Id: hal-00478925 \\ https://hal.science/hal-00478925}

Submitted on 30 Apr 2010

HAL is a multi-disciplinary open access archive for the deposit and dissemination of scientific research documents, whether they are published or not. The documents may come from teaching and research institutions in France or abroad, or from public or private research centers.
L'archive ouverte pluridisciplinaire HAL, est destinée au dépôt et à la diffusion de documents scientifiques de niveau recherche, publiés ou non, émanant des établissements d'enseignement et de recherche français ou étrangers, des laboratoires publics ou privés. 


\section{LIPID PHOSPHATE PHOSPHATASES FORM HOMO- AND HETERO-OLIGOMERS: CATALYTIC COMPETENCY, SUB-CELLULAR DISTRIBUTION AND FUNCTION}

Jaclyn S. Long, Nigel J. Pyne and Susan Pyne Cell Biology Group, SIPBS, University of Strathclyde, 27 Taylor St, Glasgow, G4 ONR, UK.

Running Title: Functional studies of lipid phosphate phosphatases

Address correspondence to: Susan Pyne, Cell Biology Group, SIPBS, University of Strathclyde, 27 Taylor St, Glasgow, G4 0NR, UK. Tel. 44-141-5482012;

FAX 44-141-5522562;

e-mail: susan.pyne@strath.ac.uk

Keywords: lipid phosphate phosphatase, phosphatidic acid, sphingosine 1-phosphate, oligomerisation, cell survival 
ABSTRACT--Lipid phosphate phosphatases (LPP1-3) have been topographically modelled as monomers (molecular mass of $31-36 \mathrm{kDa}$ ) composed of six transmembrane domains and with the catalytic site facing the extracellular side of the plasma membrane or the luminal side of intracellular membranes. The catalytic motif has three conserved domains termed $\mathrm{C1}, \mathrm{C2}$ and $\mathrm{C3}$. The $\mathrm{C} 1$ domain may be involved in substrate recognition, while $\mathrm{C2} / \mathrm{C3}$ domains appear to participate in the catalytic dephosphorylation of the substrate. We have obtained three lines of evidence to demonstrate that LPPs exist as functional oligomers. First, we have used recombinant expression and immunoprecipitation analysis to demonstrate that LPP1, LPP2 and LPP3 form both homo- and hetero-oligomers. Second, large LPP oligomeric complexes that are catalytically active were isolated using gel exclusion chromatography. Third, we demonstrate that catalytically deficient guinea pig FLAG-tagged H223L LPP1 mutant can form an oligomer with wild type LPP1 and that wild type LPP1 activity is preserved in the oligomer. These findings suggest that in an oligomeric arrangement, the catalytic site of the wild type LPP can function independently of the catalytic site of the mutant LPP. Finally, we demonstrate that endogenous LPP2 and LPP3 form homo- and hetero-oligomers, which differ in their sub-cellular localisation and which may confer differing spatial regulation of phosphatidic acid and sphingosine 1phosphate signalling.

Abbreviations: GPCR, G protein coupled receptor; IP, immunoprecipitation; LPA, lysophosphatidic acid; LPP, lipid phosphate phosphatase; PA, phosphatidic acid, S1P, sphingosine 1-phosphate; WB, Western blot; Mmyc LPP1, mutant myc-tagged LPP1; MFLAG LPP1, mutant FLAG-tagged LPP1. 


\section{INTRODUCTION}

Lipid phosphate phosphatases (LPP) are integral membrane proteins that catalyse the dephosphorylation of lipid phosphates (e.g. phosphatidic acid (PA), sphingosine 1-phosphate (S1P), lysophosphatidic acid (LPA) and ceramide 1-phosphate (C1P)) in vitro in a $\mathrm{Mg}^{2+}$ independent and N-ethylmaleimide-insensitive manner [1]. Four mammalian LPP isoforms have been cloned, termed LPP1, LPP1a, LPP2 and LPP3 [2-6], the latter corresponding to the endoplasmic reticulum protein, Dri42 that is up-regulated during differentiation of intestinal epithelial cells [7]. LPPs have been suggested to belong to a family of lipid phosphatases/phosphotransferases that also includes lipid phosphatase-related proteins (or plasticity-related genes 1-4) and sphingomyelin synthases [8]. Each LPP is predicted to have six transmembrane domains with the catalytic site, made of three conserved domains (C1-C3), facing the extracellular side of the plasma membrane or the luminal side of intracellular membranes (see Scheme 1, [9]). The plasma membrane location of LPP1, LPP1a, LPP2 and LPP3 has been detected with isoform-selective [2, 10-13] and epitope-tag antibodies [13-16]. LPP1 and LPP3 have also been identified in caveolae $[11,12]$, while LPP2 and LPP3 are present in cytoplasmic vesicles in Chinese hamster ovary $(\mathrm{CHO})$ cells [13]. LPP2 and LPP3 are constitutively colocalised with sphingosine kinase 1 (SK1) and LPP3/SK1 is re-localised to the Golgi apparatus upon induction of phospholipase D1 in CHO cells [13].

LPP have the potential to influence physiological responses to the G protein-coupled receptor (GPCR) agonists LPA and S1P. This may involve dephosphorylation of extracellular S1P and LPA via an ecto-LPP activity, which may limit bioavailability at their receptors, $\mathrm{S}_{1} \mathrm{P}_{1-5}$ and $\mathrm{LPA}_{1-3}[4,14-16]$. In addition, over-expression of LPP2 or LPP3 reduces the S1P- and LPAstimulated activation of p42/p44 MAPK in serum deprived HEK 293 cells [10, 13]. This effect is blocked by pre-treating HEK 293 cells with the caspase-3/7 inhibitor, Ac-DEVD-CHO [13]. Therefore LPP2 and LPP3 appear to regulate the apoptotic status of serum deprived HEK 293 cells. In this regard, LPP2 reduced basal intracellular phosphatidic acid levels, while LPP3 reduced intracellular S1P in serum deprived HEK 293 cells [13]. These data are consistent with an important role for LPP2 and LPP3 in regulating an intracellular pool of PA and S1P respectively that may govern apoptosis in response to cellular stress. In contrast, LPP1 has been 
implicated in reducing migration in response to PDGF in mouse embryonic fibroblasts [17] and LPA in Rat2 fibroblasts [18]. Therefore, LPP1-3 may exhibit different functions in cells.

In the current study, we have investigated the structure/functional properties of the LPP isoforms and have established that these enzymes form homo- and hetero-oligomers and are localised in distinct intracellular compartments, where they may spatially regulate phosphatidic acid and sphingosine 1-phosphate signalling.

\section{EXPERIMENTAL}

Materials--All biochemicals including dioleoyl-phosphatidic acid (dioleoyl-PA), methyl- $\beta$ cyclodextrin (M $\beta C D)$, FITC- and TRITC-conjugated secondary antibodies were from Sigma Chemical Co. (UK). Cell culture supplies and LipofectAMINE ${ }^{\mathrm{TM}} 2000$ were from Invitrogen (Paisley, UK). Anti-FLAG epitope and anti-myc epitope tag antibodies were from Stratagene and Santa Cruz Biotechnology Inc (USA). [ $\left.{ }^{32} \mathrm{P}-\gamma\right]$ ATP was purchased from GE Healthcare (UK). $\left[{ }^{32} \mathrm{P}\right]$-Dioleoyl-PA was prepared as described previously [10]. Affinity purified anti-LPP2 and anti-LPP3 antibodies were prepared as described previously [10].

Cell Culture--HEK 293 cells were maintained in minimum essential medium (MEM), supplemented with foetal calf serum $(10 \%, \mathrm{v} / \mathrm{v})$ and penicillin/streptomycin. CHO cells were maintained in Ham's F12 medium supplemented with foetal calf serum $(10 \%, \mathrm{v} / \mathrm{v})$ and penicillin/streptomycin.

LPP Constructs--LPPs were separately amplified from pcDNA3.1 constructs encoding gpLPP1, hLPP2 and hLPP3 [10] using gene specific primers encoding a C-terminal myc epitope tag (EQKLISEEDL) or FLAG epitope tag (DYKDHDGDYKDHD) and inserted into pcDNA3.1. Myc-epitope tagged R127K LPP1 and FLAG-epitope tagged H223L LPP1 were generated by site-directed mutagenesis.

Transfection--HEK 293 cells were transiently transfected with LPP plasmid constructs as required. Cells at $75-95 \%$ confluence were placed in medium containing $1 \%$ FCS and transfected with $1 \mu \mathrm{g}$ plasmid construct following complex formation with LipofectAMINE ${ }^{\mathrm{TM}} 2000$, 
according to the Manufacturer's instructions. The cDNA containing media was removed after incubation for 24 hours at $37^{\circ} \mathrm{C}$, and the cells incubated for a further 18 hours in serum free medium prior to experiments. Where indicated, cells were treated with $\mathrm{M} \beta C D(10 \mathrm{mM}, 60 \mathrm{~min})$ prior to lysis and immunoprecipitation.

Immunoprecipitation--The medium was removed and cells lysed in ice-cold immunoprecipitation buffer $(1 \mathrm{ml})$ containing $20 \mathrm{mM}$ Tris/ $\mathrm{HCl}, 137 \mathrm{mM} \mathrm{NaCl}, 2.7 \mathrm{mM} \mathrm{KCl}, 1 \mathrm{mM}$ $\mathrm{MgCl}_{2}, 1 \mathrm{mM} \mathrm{CaCl} 2,1 \%$ (v/v) Nonidet P-40 (NP-40), 10\% (v/v) glycerol, 1mg/ml BSA, 0.5mM sodium orthovanadate, $0.2 \mathrm{mM}$ PMSF, leupeptin, antipain, pepstatin and aprotinin [all protease inhibitors were at $10 \mu \mathrm{g} / \mathrm{ml}$ ] for 75 minutes at $4{ }^{\circ} \mathrm{C}$. The material was harvested, centrifuged at $22000 \mathrm{~g}$ for 10 minutes at $4^{\circ} \mathrm{C}$ and $200 \mu \mathrm{l}$ of cell lysate supernatant (equalised for protein, 0.5 $1 \mathrm{mg} / \mathrm{ml})$ taken for immunoprecipitation with anti-FLAG tag or anti-myc tag antibodies $(2 \mu \mathrm{g}$ of antibody and $20 \mu \mathrm{l}$ of 1 part immunoprecipitation buffer and 1 part protein A Sepharose CL4B) as required. After agitation for 2 hours at $4^{\circ} \mathrm{C}$, the immune complex was collected by centrifugation at $22000 \mathrm{~g}$ for 15 seconds at $4^{\circ} \mathrm{C}$. Immunoprecipitates were washed twice with buffer $\mathrm{A}$

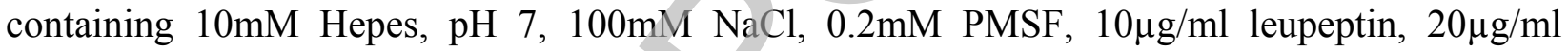
aprotinin and 0.5\% (v/v) NP-40 and once in buffer A without NP-40. The immunoprecipitates were then combined with boiling sample buffer and subjected to SDS-PAGE and Western blotting.

SDS-PAGE and Western Blotting--Cell lysates were prepared using sample buffer containing 62mM-Tris $\mathrm{HCl}, \mathrm{pH} 6.7,1.25 \%$ (w/v) SDS, 10\% (v/v) glycerol, 3.75\% (v/v) mercaptoethanol and $0.05 \%(\mathrm{w} / \mathrm{v})$ bromophenol blue and proteins resolved by SDS-PAGE. Western blotting with specific antibodies was used to identify proteins of interest [10]. Immunoreactive proteins were visualised using enhanced chemiluminescence detection.

Immunofluorescence--Cells were grown on $12 \mathrm{~mm}$ glass coverslips to $60-90 \%$ confluence and transfected as described above. Cells were fixed in 3.7\% formaldehyde in PBS for 10 minutes then permeabilised in $0.1 \%$ Triton X100 in phosphate buffered saline for 1 minute. Non-specific binding was reduced by pre-incubating cells in blocking solution containing $5 \% \mathrm{FCS}, 1 \% \mathrm{BSA}$ in 
phosphate buffered saline for 1hour. Cells were incubated in primary antibody (1:100 dilution in blocking solution) for 1 hour at room temperature (or overnight at $4^{\circ} \mathrm{C}$ ) and then incubated with the appropriate TRITC- or FITC-conjugated secondary antibody (1:100) for 1 hour. Cells were mounted on glass slides using Vectashield mounting medium and visualised using a Nikon E600 epi-fluorescence microscope.

LPP Activity--Membranes of HEK 293 cells, which had been transiently transfected with LPP plasmid constructs, were prepared by homogenization in ice-cold buffer (containing 50mM Trismaleate, $1 \mathrm{mM}$ EDTA, $150 \mathrm{mM} \mathrm{NaCl}$, and $10 \mathrm{mM}$ mercaptoethanol) and centrifugation at $22000 \mathrm{~g}$ at $4{ }^{\circ} \mathrm{C}$ for $10 \mathrm{~min}$. Pellets were resuspended in homogenization buffer (at 20-200 $\mathrm{mg}$ of protein $/ \mathrm{ml}$ ) and stored at $-20{ }^{\circ} \mathrm{C}$. Membrane LPP activity was measured as the liberation of $\left[{ }^{32} \mathrm{Pi}\right]$ from $\left[{ }^{32} \mathrm{P}\right]$-labeled PA $(500 \mu \mathrm{M}, 1000 \mathrm{dpm} / \mathrm{pmol}-625 \mathrm{dpm} / \mathrm{nmol})$ in the presence of Triton X-100 (fixed lipid:detergent ratio of $1: 10$ ), $37.5 \mathrm{mM}$ Tris-maleate, $7.5 \mathrm{mM}$ mercaptoethanol, and 0.2 $\mathrm{mg} / \mathrm{ml}$ bovine albumin at $30{ }^{\circ} \mathrm{C}$ for $5 \mathrm{~min}$. Incubations were stopped by the addition of 5 volumes of chloroform/methanol/10 $\mathrm{mM} \mathrm{HCl}(15: 30: 2, \mathrm{v} / \mathrm{v})$. Organic and aqueous phases were resolved by the addition of 1.25 volumes each of chloroform and $0.1 \mathrm{M} \mathrm{HCl}$. Liberated [ $\left.{ }^{32} \mathrm{Pi}\right]$ was measured by counting radioactivity in the upper phase. All assays were performed under conditions where less than $10 \%$ of the substrate was dephosphorylated. Anti-FLAG tag antibody immunoprecipitates were assayed similarly.

Chromatography--Approximately $10^{7}$ HEK 293 cells (separately transiently transfected with plasmid constructs encoding FLAG tagged-LPP1, -LPP2 or -LPP3) were lysed in $1 \mathrm{ml}$ of buffer containing $50 \mathrm{mM}$ HEPES, $100 \mathrm{mM}$ NaCl, $5 \mathrm{mM}$ EDTA, $1 \mathrm{mM}$ PMSF, $46 \mathrm{mM} \beta-$ octylglucopyranoside (or $1 \%$ Triton $\mathrm{X}-100)$ and $10 \mu \mathrm{g} / \mathrm{ml}$ each of leupeptin and aprotinin (pH 7.5) and mixed end over end for $60 \mathrm{~min}$. A high speed supernatant was prepared by centrifugation at $100000 \mathrm{~g}$ for $60 \mathrm{~min}$. $100 \mu \mathrm{l}$ of this was applied to a Superose 12 column and eluted at $0.3 \mathrm{ml} / \mathrm{min}$ using $50 \mathrm{mM}$ HEPES, $150 \mathrm{mM} \mathrm{NaCl}, 1 \mathrm{mM}$ EDTA (pH 7). $50 \mu \mathrm{l}$ of the resulting $0.5 \mathrm{ml}$ fractions were assayed for LPP activity as described above except that samples were incubated for $60 \mathrm{~min}$. Samples were also subjected to acid precipitation and Western blotting with anti-FLAG tag antibody. 


\section{RESULTS AND DISCUSSION}

LPP Form both Homo- and Hetero-oligomers--We investigated the possibility that LPPs form oligomeric complexes and have assessed whether this molecular arrangement is necessary for catalytic competency. The rationale for this approach was provided by several studies. For instance, Siess and Hofstetter have reported that the Stokes radius of LPP is consistent with a hexameric arrangement of subunits [19]. Additionally, X-ray analysis of a related non-specific acid phosphatase from $E$. blattae demonstrated that this enzyme exists as hexamer of three identical dimers [20]. Wunen, a Drosophila LPP homologue has also been demonstrated to form dimers [21].

HEK 293 cells were transiently transfected with plasmid constructs encoding C-terminal myctagged and/or FLAG-tagged LPPs and subjected to immunoprecipitation with respective antibodies to test whether LPP1-3 can form homo- and hetero-oligomers in intact cells. Western blot analysis of cell lysates established that FLAG-tagged and myc-tagged LPP1 were expressed in HEK 293 cells as three major proteins with $\mathrm{Mr}=31,34.5$ and $35 \mathrm{kDa}$ (Fig. 1a), suggesting that the recombinant enzyme undergoes post-translation modification. FLAG-tagged and myc-tagged LPP2 was expressed as a smeared protein on SDS-PAGE with a Mr=33-36kDa (Fig. 1a), while FLAG-tagged and myc-tagged LPP3 was expressed as three major proteins of $\mathrm{Mr}=32,34$ and 36kDa in HEK 293 cells (Fig. 1a).

We demonstrate here that myc-tagged LPP1 can be co-immunoprecipitated with FLAG-LPP1 using anti-FLAG antibody (Fig. 1b, left panel). We also used immunoprecipitation analysis to demonstrate that LPP2 and LPP3 form homo-oligomers (Fig. 1b, left panels) and that LPP1, LPP2 and LPP3 form hetero-oligomers with each other (Fig. 1b, centre and right panels). Identical results were obtained using anti-myc antibody (Fig. 1b, lower panel), confirming the formation of LPP1, LPP2 and LPP3 homo-oligomers and LPP2/LPP3 hetero-oligomers. Formation of oligomers of epitope-tagged LPPs requires their co-expression in an intact cell system. This conclusion was based on evidence showing that combining lysates from cells separately transfected with each plasmid construct did not result in formation of FLAG-tagged LPP/myc-tagged LPP oligomers (Fig. 1c). We also considered the possibility that LPPs may be 
localised to discrete lipid rafts in close proximity, but are not physically associated. If this were the case, then anti-FLAG or anti-myc tag antibody might 'pull down' the lipid raft containing both tagged forms. However, we rejected this possibility as cholesterol depletion from cell membranes using $\mathrm{M} \beta \mathrm{CD}$ to destroy lipid rafts did not prevent co-immunoprecipitation of myctagged LPP1 with FLAG-tagged LPP3 using anti-FLAG antibody (Fig. 1d).

Additional evidence for an interaction between LPPs was evident from immunofluorescent cell imaging experiments. These experiments demonstrated that recombinant myc-LPP1/FLAGLPP2, FLAG-LPP1/myc-LPP3 and myc-LPP2/FLAG-LPP3 are co-localised at the plasmamembrane and in a perinuclear region of HEK 293 cells (as shown by yellow immunofluorescence in the merged panels, Fig. 2a-c).

Elution Properties of LPP Isoforms--Oligomerisation will increase the apparent molecular mass above the monomeric molecular mass of LPPs, determined by cloning (31-36 kDa). One method to establish this is by using gel exclusion chromatography. Therefore, we specifically assessed whether we could separate both oligomeric and monomeric LPP species using Superose 12 chromatography. Membranes from HEK 293 cells transiently transfected with plasmid constructs encoding FLAG tagged-LPP1, -LPP2 or -LPP3 were subjected solubilisation using $\beta$ octylglucopyranoside (Fig. 3a-c).

Immunoblotting fractions eluted from Superose 12 with anti-FLAG antibody revealed the presence of $31 \mathrm{kDa}, 34.5 \mathrm{kDa}$ and $35 \mathrm{kDa}$ forms of FLAG-tagged LPP1 in fractions 13-16 eluting after Blue Dextran (fraction 12, molecular mass 2000kDa) (Fig. 3a). FLAG tagged 34.5kDa LPP1 was also detected in fractions 28-30 that correspond to a molecular size consistent with monomeric LPP1 (Fig. 3a). LPP1 monomers might therefore, exist in equilibrium with oligomeric LPP1. In addition, the 31 and $35 \mathrm{kDa}$ forms of LPP1 do not appear to exist as monomers. 31 and $35 \mathrm{kDa}$ LPP1 might therefore be sequentially modified and produced from $34.5 \mathrm{kDa}$ LPP1 when this latter form is initially assembled as an oligomer. LPP1 activity was associated with the high molecular mass complex (Fig. 3a), with no activity being detected in fractions containing $34.5 \mathrm{kDa}$ monomer. This might suggest that the monomeric LPP1 is inactive or that it is inactivated during the gel filtration step. 
We also detected 33-36kDa FLAG-tagged LPP2 in fractions corresponding to a high molecular mass complex and which co-eluted with LPP activity. A $34 \mathrm{kDa}$ form was also present in the low molecular mass fraction and was devoid of LPP activity (Fig. 3b). 32kDa, 34kDa and 36kDa forms of FLAG-tagged LPP3 and activity were also detected in fractions corresponding to a high molecular mass, while the $34 \mathrm{kDa}$ form was present in the low molecular mass fraction and was devoid of activity (Fig. 3c). We also considered the possibility that recombinant LPPs might behave differently compared with endogenous LPP and that oligomerisation might be a property unique to recombinant enzyme. However, endogenous LPP activity (from vector-transfected cells) was also detected in high molecular mass fractions isolated from Superose 12 chromatography (Fig. 3d).

Western blots of elution profiles of FLAG-tagged-LPP1, -LPP2 or -LPP3 (Fig. 3e) and activity measurements (data not shown) were similar when a different detergent, Triton X-100, was used. This suggests that micellar size (90kDa for Triton X-100 and 30kDa for $\beta$-octylglucopyranoside) does not account for elution of LPP activity in high molecular mass fractions, i.e. in large micelles containing monomeric LPP.

These results suggest that oligomerisation and/or subsequent post-translational modification, such as glycosylation might result in formation of competent catalytic sites. Phosphorylation of LPPs has proven difficult to demonstrate and glycosylation has been excluded as a requirement for catalytic activity as site-directed mutagenesis of the glycosylation site in LPP1 has previously been shown to have no effect on activity [9]. Therefore, we focussed on the possibility that the oligomerisation itself might confer competency on the catalytic site(s).

Catalytic Activity and Oligomerisation--Three highly conserved domains (C1-C3) that constitute the catalytic site have been identified in the phosphatase superfamily that includes bacterial acid phosphatase, yeast and bacterial diacylglycerol pyrophosphatase, fungal chloroperoxidase, mammalian glucose 6-phosphate phosphatase and the Drosophilia protein Wunen. [22]. The C1C3 domains have been mapped to the proposed extra-membrane loops 3 and 5 of LPP1 (Scheme 1). Mutation of the conserved amino acids K120R, R127K, P128I (C1 domain), S169T, H171L 
(C2 domain), R217K, H223L (C3 domain) of murine LPP1 substantially reduce catalytic activity [9]. C2 and C3 domains are involved in lipid phosphate phosphatase/phosphotransferase activity while the $\mathrm{C} 1$ domain might be a substrate recognition site [8]. The latter is based on the fact that this region is replaced in sphingomyelin synthase, which functions as a phosphotransferase and displays a different substrate preference compared with LPP [8].

We considered the simplest model in which dimers are formed and these are then organised in an oligomeric arrangement. In this model, it is possible that the $\mathrm{C} 1, \mathrm{C} 2$ and $\mathrm{C} 3$ domains in each LPP monomer form two competent catalytic sites by domain swapping between the monomers. This can be achieved if the two catalytic sites are formed in a 'back to front' orientation (e.g. C1 from monomer A, conferring substrate binding, is shared with $\mathrm{C} 2$ and $\mathrm{C} 3$ from monomer $\mathrm{B}$, conferring catalytic activity, and vice versa). Therefore, we created catalytically deficient myctagged R127K LPP1 (C1 mutagenesis) and FLAG-tagged H223L LPP1 (C3 mutagenesis) mutants (cell membrane LPP1 fold activity increase above mock transfected: FLAG-tagged WT LPP1, $79.5 \pm 6.3$ fold; Myc-tagged WT LPP1, $30.2 \pm 2$ fold; FLAG-tagged H223L LPP1, $2.3 \pm$ 0.25 fold; myc-tagged R127K LPP1, $2 \pm 0.48$ fold). We predicted that if dimerisation involves domain swapping between the monomers to form two catalytic sites then co-expression of the two catalytic deficient LPP1 forms, mutated in $\mathrm{C} 1$ and $\mathrm{C} 3$ domains, respectively, should theoretically form one competent catalytic site and reconstitute $\sim 50 \%$ of the WT LPP1 activity at equivalent expression level. However, when these mutants were co-expressed (and coimmunoprecipitated with anti-FLAG antibody), we detected negligible LPP1 activity (Fig. 4), i.e. $\sim 2 \%$ of the activity measured in immunoprecipitates derived from cells co-expressing FLAGtagged and myc-tagged WT LPP1 (see Fig. 4, western blot for $\sim$ equivalent amounts of wild type and mutant LPP1 recovered in anti-FLAG immunoprecipitates).

Myc-tagged WT LPP1 was co-immunoprecipitated with catalytically deficient FLAG-tagged H223L LPP1 (from cells co-expressing both forms) using anti-FLAG-tag antibody (Fig. 4, inset). Moreover, significant LPP1 activity was detected in the immunoprecipitate (Fig. 4, 40\% of the activity measured in anti-FLAG tag immunoprecipitates derived from cells co-expressing FLAGtagged WT LPP1 and myc-tagged WT LPP1). As a control we found that anti-FLAG immunoprecipitates prepared from lysates of cells over-expressing wild type myc-tagged LPP1 
alone had negligible LPP1 activity (data not shown) and no detectable myc-tagged WT LPP1 on Western blots (Fig. 1b, left panel). The findings therefore, suggest that in an oligomeric arrangement, the catalytic site of the WT enzyme can function independently of the catalytic site of the mutant. If dimers are formed between WT and mutant enzyme, we can conclude from these data that dimerisation is not required for catalytic competency. However, we cannot definitively rule out that there is a close arrangement of separate WT and mutant LPP dimers and that these are 'pulled down' together by anti-FLAG antibody. In this case, we cannot exclude dimerisation as a mechanism for formation of catalytic competent sites, except that it is unlikely that these are formed using domain swapping in a 'back to front' orientation.

The results which show that catalytic deficient myc-tagged R127K LPP1 and FLAG-tagged H223L LPP1 can form oligomers (Fig. 4) might suggest that full catalytic activity is not required for oligomerisation. However, in the case of Wunen, there is evidence to indicate that catalytic activity is required for dimerisation, but not for in vivo function [21].

Endogenous LPP2 and LPP3 Form a Complex--We have shown here that endogenous LPP elutes as a high molecular mass oligomer from Superose 12 chromatography. However, we sought additional evidence that the endogenous LPPs undergo oligomerisation. Toward this end, we found that the endogenous forms of LPP2 and LPP3 are present in complexes in CHO cells (Fig. 5). The enzymes exhibit different patterns of post-translational modification and subcellular localisation compared with recombinant LPPs expressed in HEK 293 cells. LPP3 is expressed as two major proteins in CHO cells with molecular masses of 32 and 34kDa, while LPP2 has a molecular mass of $33 \mathrm{kDa}$. Co-immunoprecipitation analysis using anti-LPP2 or antiLPP3 antibodies (that are specific for each LPP isoform respectively [10, 13]) demonstrated that LPP2 forms a complex with the $32 \mathrm{kDa}$ form of LPP3 but not the $34 \mathrm{kDa}$ form (Fig. 5).

The presence of the endogenous LPP2/ LPP3 (32kDa) hetero-oligomer in CHO cells suggests a functional role for this oligomer. In this respect, we have drawn on results previously obtained in our laboratory concerning the sub-cellular distribution of LPP2 and LPP3 in CHO cells. We have previously shown that endogenous LPP2 or LPP3 are localised in cytoplasmic vesicles in CHO cells. However, in $\mathrm{CHO}$ cells stimulated with PMA (which activates Golgi apparatus associated 
PLD1), a discrete pool of LPP3 is re-localised to the Golgi apparatus [13]. We have also obtained similar results in CHO cells expressing inducible PLD1 (PLD1 is induced by doxycycline), and ectopically expressing recombinant LPP3 [13]. Thus, induction of PLD1 is associated with a redistribution of LPP3 (which is normally co-localised with sphingosine kinase1 (SK1) in cytoplasmic vesicles) to the Golgi apparatus. We do not know whether this involves increased movement of LPP3 and SK1 to the Golgi apparatus or whether trafficking of these proteins away from the Golgi apparatus is reduced. Nevertheless, this re-localisation appears to be important as over-expression of LPP3 reduces intracellular S1P levels and this leads to the onset of apoptosis in HEK 293 cells [13]. We have also shown that SK1 interacts with PLDderived PA (via a PA binding domain in SK1) [23]. Therefore, the redistribution of LPP3 might represent a physiological desensitisation mechanism for controlling the PLD1-SK1 interaction and S1P formation in the Golgi apparatus. This discrete pool of LPP3 may be comprised of both the $34 \mathrm{kDa}$ and $/$ or $32 \mathrm{kDa}$ forms.

Additionally, we have previously demonstrated that endogenous LPP2 does not traffic to or from the Golgi apparatus upon PMA stimulation of CHO cells or upon induction of PLD1, although it is also co-localised with SK1 in cytoplasmic vesicles [13] and, as we show here, can form a complex with 32kDa LPP3 (Fig. 5). We have shown that over-expression of LPP2 reduces intracellular PA and have suggested that this might prevent its movement to or entrapment with SK1 at the Golgi apparatus upon PLD1 activation [13]. Under these conditions, this may involve predominantly LPP2 homo-oligomers. Endogenous LPP2/LPP3 (32kDa) hetero-oligomers may regulate PA and/or S1P concentrations in cytoplasmic vesicles, given their co-localisation with SK1 [13]. In conclusion, we suggest that LPP oligomers might regulate compartmentalised pools of S1P and PA and contribute to the spatial signalling by these lipids within cells.

\section{Acknowledgments}

This work was supported by an ORS studentship to JL.

\section{REFERENCES}

1. Brindley, D.N. and Waggoner, D.W. (1998) Mammalian lipid phosphate phosphohydrolases. J. Biol. Chem. 273, 24281-25284 
2. Kai, M., Wada, I., Imai, S., Sakane, F. and Kanoh, H. (1996) Identification and cDNA cloning of 35-kDa phosphatidic acid phosphatase (type 2) bound to plasma membranes. J. Biol. Chem. 271, 18931-18938

3. Kai, M., Wada, I., Imai, S., Sakane, F. and Kanoh, H. (1997) Cloning and characterisation of two human isozymes of $\mathrm{Mg}^{2+}$-independent phosphatidic acid phosphatase. J. Biol. Chem. 272, 24572-24578

4. Roberts, R., Sciorra, V.A. and Morris, A.J. (1998) Human type 2 phosphatidic acid phosphohydrolases: substrate specificity of the type $2 \mathrm{a}, 2 \mathrm{~b}$ and $2 \mathrm{c}$ enzymes and cell surface activity of the 2a isoform. J. Biol. Chem. 273, 22059-22067

5. Tate, R., Tolan, D. and Pyne, S. (1998) Molecular cloning of magnesium-independent type 2 phosphatidic acid phosphatases from airway smooth muscle. Cell Signaling 11, $515-522$

6. Leung, D.W., Tompkins, C.K. and White, T. (1998) Molecular cloning of two alternatively spliced forms of human phosphatidic acid phosphatase cDNA that are differentially expressed in normal and tumour cells. DNA. Cell. Biol. 17, 377-385

7. Barilá, D., Plateroti, M., Nobili, F., Onetti Muda, A., Xie, T., Morimoto, G. and Perozzi, G. (1996) The Dri 42 gene, whose expression is up-regulated during epithelial differentiation, encodes a novel endoplasmic resident transmembrane protein. J. Biol. Chem. 271, 29928-36

8. Sigal, Y.J., McDermott, M.I. and Morris, A.J. (2005) Integral membrane lipid phosphatases/phosphotransferases: common structure and diverse functions. Biochem. J. 387, 281-293

9. Zhang, Q.X., Pilquil, C.S., Dewald, J., Berthiaume, L.G. and Brindley, D.N. (2000) Identification of structurally important domains of lipid phosphate phosphatase-1: implications for its sites of action. Biochem. J. 345, 181-184

10. Alderton, F.A., Darroch, P., Sambi, B., McKie, A., Ahmed, I.S., Pyne, N.J. and Pyne, S. (2001) G protein-coupled receptor stimulation of the p42/p44 mitogen-activated protein kinase pathway is attenuated by lipid phosphate phosphatase 1, 1a and 2 in HEK 293 cells. J. Biol. Chem. 276, 13452-13460 
11. Sciorra, V.A. and Morris, A.J. (1999) Sequential actions of phospholipase D and phosphatidic acid phosphohydrolase $2 \mathrm{~b}$ generate diglyceride in mammalian cells. Mol. Cell Biol. 10, 3863-3876

12. Nanjundan, M. and Possmayer, F. (2001) Pulmonary lipid phosphate phosphohydrolase in plasma membrane signalling platforms. Biochem. J. 358, 637-646

13. Long, J., Darroch, P.I., Wan, K.F., Kong, K.C., Ktistakis, N.T., Pyne, N.J. and Pyne, S. (2005) Regulation of cell survival by lipid phosphate phosphatases involves the modulation of intracellular phosphatidic acid and sphingosine 1-phosphate pools. Biochem. J. 391, 25-32

14. Jasinska, R., Zhang, Q.X., Pilquil, C.S., Singh, I., Xu, J., Dewald, J., Dillon, D.A., Bertiaume, L.G., Carman, G.M., Waggoner, D.W. and Brindley, D.N. (1999) Lipid phosphate phosphohydrolase-1 degrades exogenous glycerolipid and sphingolipid phosphate esters. Biochem. J. 340, 677-686

15. Ishikawa,T., Kai, M., Wada, I. and Kanoh, H. (2000) Cell surface activities of the human type $2 \mathrm{~b}$ phosphatidic acid phosphatase. J. Biochem. 127, 645-651

16. Jia, Y-J., Kai, M., Wada, I., Sakane, F. and Kanoh, H. (2003) Differential localisation of lipid phosphate phosphatases 1 and 3 to cell surface subdomains in polarised MDCK cells. FEBS Lett. 552, 240-246

17. Long, J.S., Yokoyama, K., Tigyi, G., Pyne, N. J. \& Pyne, S. (2006) Lipid phosphate phosphatase-1 regulates lysophosphatidic acid- and platelet-derived growth factorinduced cell migration. Biochem. J. 394, 495-500

18. Pilquil, C., Dewald, J., Cherney, A., Gorshkova, I., Tigyi, G., English, D., Natarajan, V. and Brindley, D.N. (2006) Lipid phosphate phosphatase-1 regulates lysophosphatidateinduced fibroblast migration by controlling phospholipase D2-dependent phosphatidate generation. J. Biol. Chem. 281, 38418-38429

19. Siess, E.A. and Hofstetter, M.M. (1996) Identification of phosphatidate phosphohydrolase purified from rat liver membranes on SDS-polyacrylamide gel electrophoresis. FEBS Lett. 381, 169-173

20. Ishikawa, K., Mihara, Y., Gondoh, K., Suzuki, E. and Asano, Y. (2003) X-ray structures of a novel acid phosphatase from Escherichia blattae and its complex with the transitionstate analog molybdate. EMBO J. 19, 2412-2423 
21. Burnett, C., Makridou, P., Hewlett, L. and Howard, K. (2004) Lipid phosphate phosphatases dimerise, but this interaction is not required for in vivo activity. BMC Biochemistry 5, 2

22. Stukey, J. and Carman, G.M. (1997) Identification of a novel phosphatase sequence motif. Protein Sci. 6, 469-472

23. Delon, C., Manifava, M., Wood, E., Thompson, D., Krugmann, S., Pyne, S. and Ktistakis, N.T. (2004) Sphingosine kinase 1 is an intracellular effector of phosphatidic acid. J. Biol. Chem. 279, 44763-44774

\section{FIGURE LEGENDS}

Scheme 1 Predicted topography of LPP structure and amino acid sequence of conserved domains. The catalytic motif is predicted to be made of three conserved domains $(\mathrm{C} 1-\mathrm{C} 3)$ in the third and fifth extramembrane loops. Amino acids in C1-C3 of LPP1, LPP2 and LPP3 that are required for catalysis and conserved within a phosphatase superfamily are indicated in bold.

Fig. 1 Homo- and hetero-oligomerisation of LPP1, LPP2 and LPP3. HEK 293 cells were transiently transfected with plasmid constructs encoding myc-tagged and/or FLAG-tagged LPP1 and/or LPP2 and/or LPP3. (a) Western blot showing the expression of epitope-tagged LPP1, LPP2 and LPP3 in HEK 293 cells, detected with anti-FLAG tag and anti-myc-tag antibodies; (b) Western blot of anti-FLAG tag or anti-myc tag immunoprecipitates demonstrating homo- and hetero-oligomersation of LPP1, LPP2 and LPP3; (c) Western blot of anti-FLAG tag or anti-myc tag immunoprecipitates from combined lysates of cells separately transfected with myc-tagged and FLAG-tagged LPP plasmid constructs; (d) Western blot of anti-FLAG tag immunoprecipitates from lysates of cells co-transfected with myc-tagged LPP1 and FLAGtagged LPP3 plasmid constructs and demonstrating that M $\beta C D$-treatment of cells to disrupt lipid rafts does not affect oligomerisation.

Fig. 2 Co-localisation of recombinant epitope tagged LPP1, LPP2 and LPP3 heterooligomers in HEK 293 cells. HEK 293 cells were transiently transfected with plasmid constructs encoding myc-tagged and FLAG-tagged versions of LPP1 and/or LPP2 and/or LPP3. 
Immunofluorescent cell imaging with anti-myc tag (FITC-conjugated secondary antibody, green) and anti-FLAG tag (TRITC-conjugated secondary antibody, red) antibodies showing colocalisation of (a) LPP1/LPP2; (b) LPP1/LPP3; (c) LPP2/LPP3.

Fig. 3 Gel exclusion chromatography of LPP. Superose 12 gel exclusion chromatography of (a-d) $\beta$-octylglucopyranoside or (e) Triton-X100 solubilised membranes from HEK 293 cells that have been transiently transfected with plasmid constructs encoding: (a) FLAG-tagged LPP1 or (b) FLAG-tagged LPP2 or (c) FLAG-tagged LPP3 or (d) vector. Chromatographic fractions were subjected LPP activity assays (a-d) using dioleolyl-PA and Western blotted (a-c, e) with anti-FLAG antibody. (a-c) show FLAG-LPP activity, i.e. from which endogenous LPP activity of vector transfected cells (d) has been subtracted. Markers were Blue dextran, $2000 \mathrm{kDa}$; albumin, $67 \mathrm{kDa}$.

Fig. 4 LPP oligomerisation and competency of enzyme catalysis. HEK 293 cells were transfected with plasmid construct encoding catalytically deficient myc-tagged R127K LPP1 (C1 mutagenesis) and/or FLAG-tagged H223L LPP1 and/or FLAG tagged and/or myc-tagged WT LPP1. LPP activity (nmol/min, mean $\neq$ S.E.M., $n=4)$ was measured in anti-FLAG immunoprecipitates. The corresponding western blot of anti-FLAG immunoprecipitates probed with anti-myc tag or anti-FLAG tag antibody is shown.

Fig. 5 Endogenous LPP2/LPP3 homo- and hetero-oligomer formation in CHO cells. Western blot of anti-LPP2 and anti-LPP3 immunoprecipitates from CHO cells showing heterooligomerisation of endogenous LPP2 and LPP3. (-) represents immunoprecipitation performed with no primary antibody. 


\section{Scheme 1}

\section{Catalytic domain}

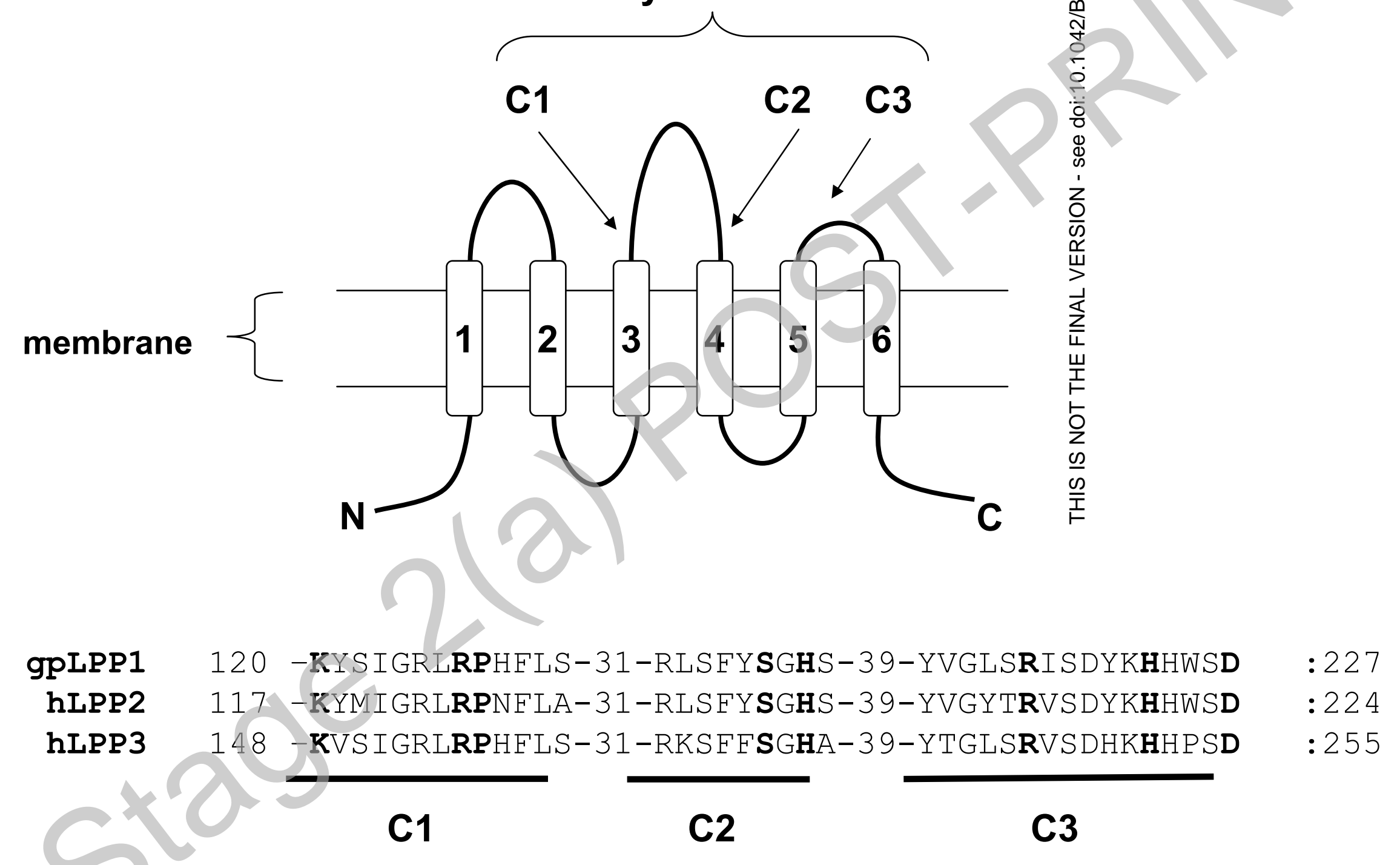


Fig. 1a

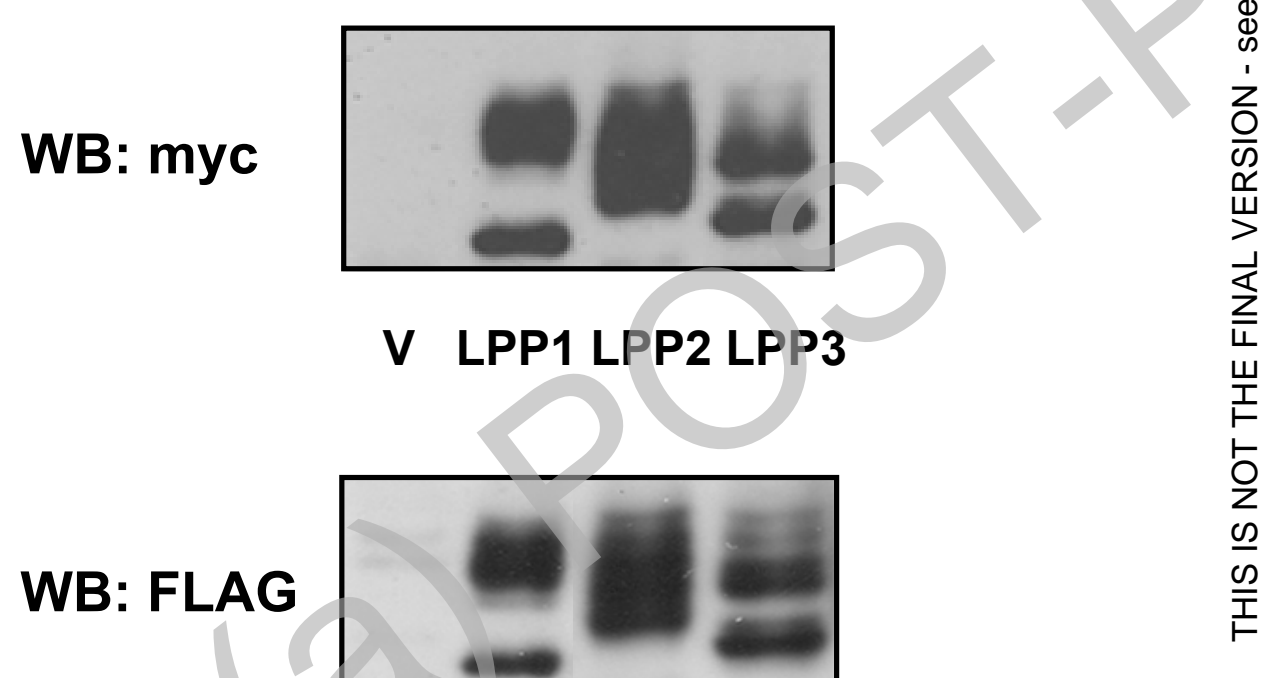


Fig. 1b

\section{IP: FLAG}

WB: myc
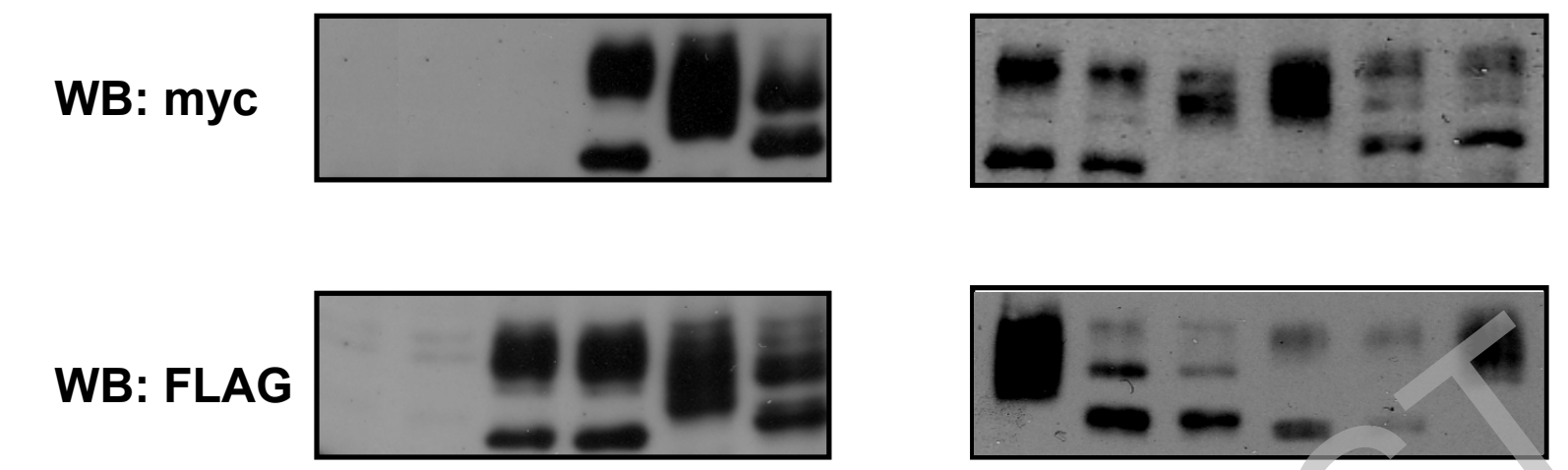

$\begin{array}{lcccccc}\text { Vector (myc) } & + & - & + & - & - & - \\ \text { Vector (FLAG) } & + & + & - & - & - & - \\ \text { Myc LPP } & - & 1 & - & 1 & 2 & 3 \\ \text { FLAG LPP } & - & - & 1 & 1 & 2 & 3\end{array}$
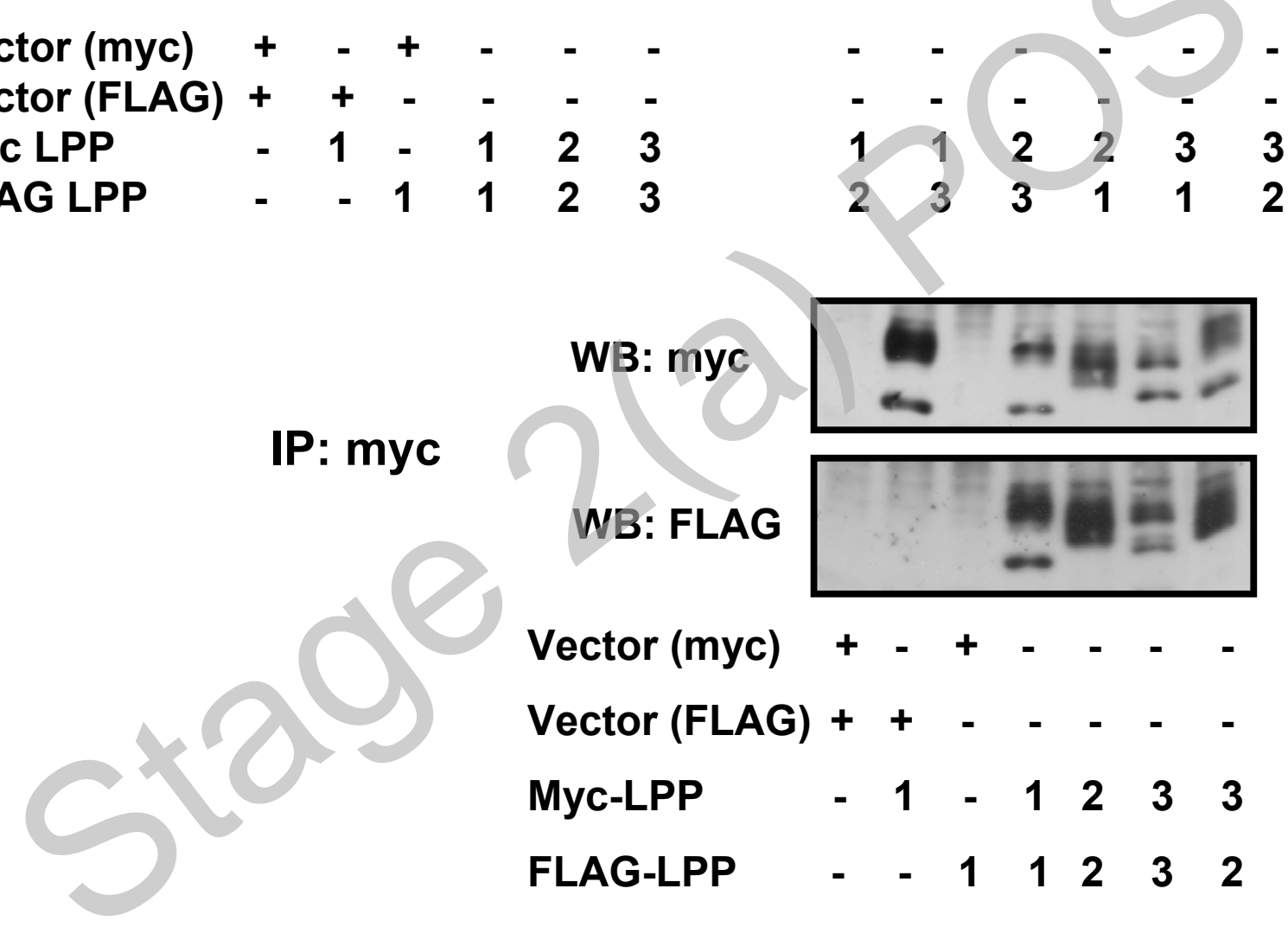
Fig. 1c

IP: myc

WB:FLAG
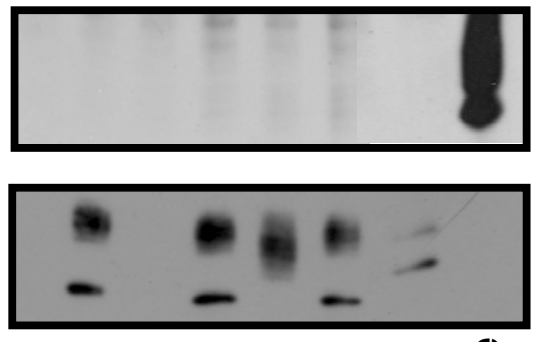

Vector (myc)

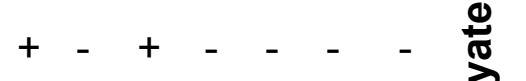

Vector (FLAG)

Myc-LPP

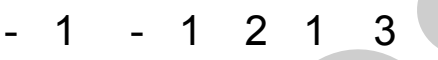

FLAG-LPP

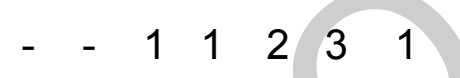

\.

IP: FLAG
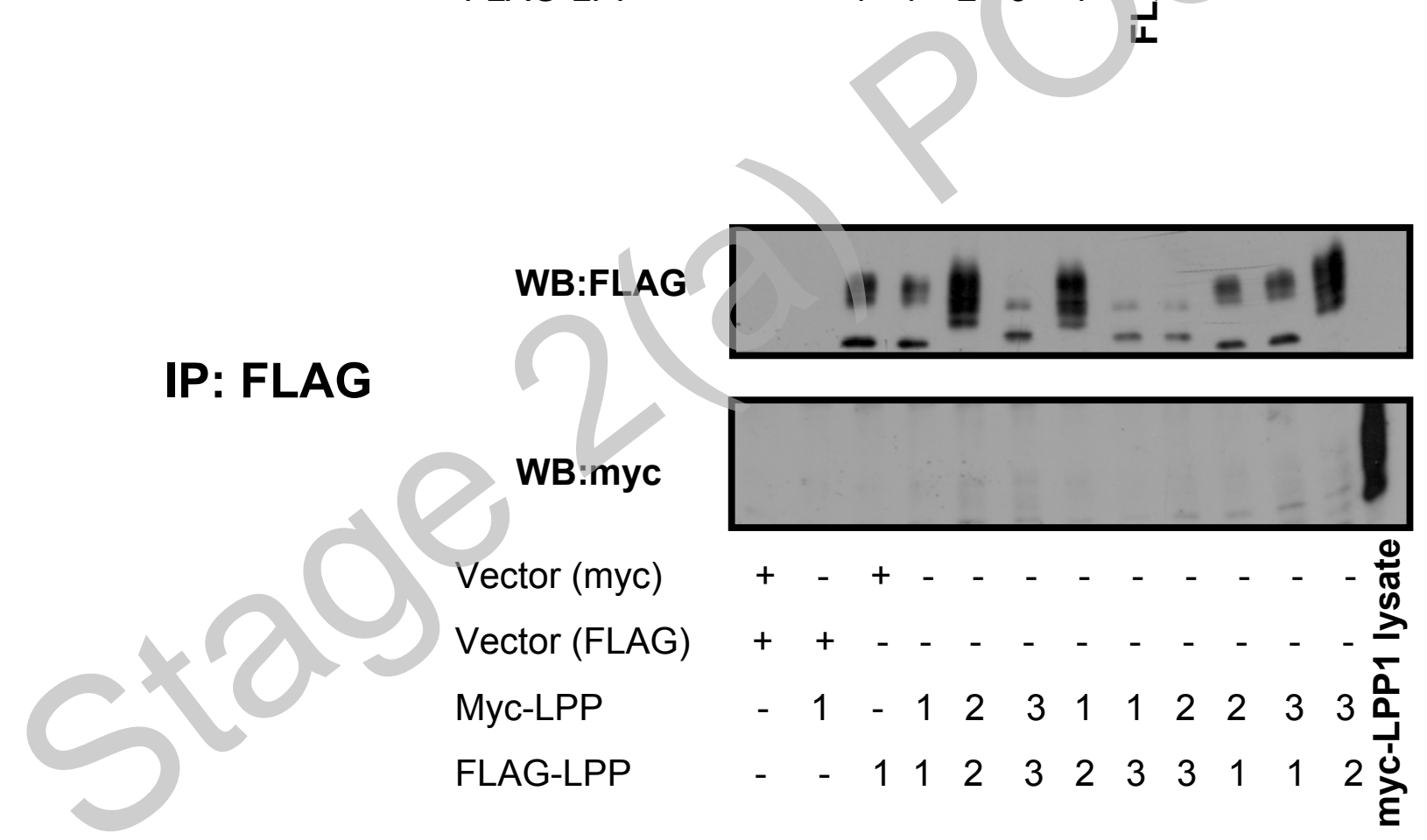
Fig. 1d

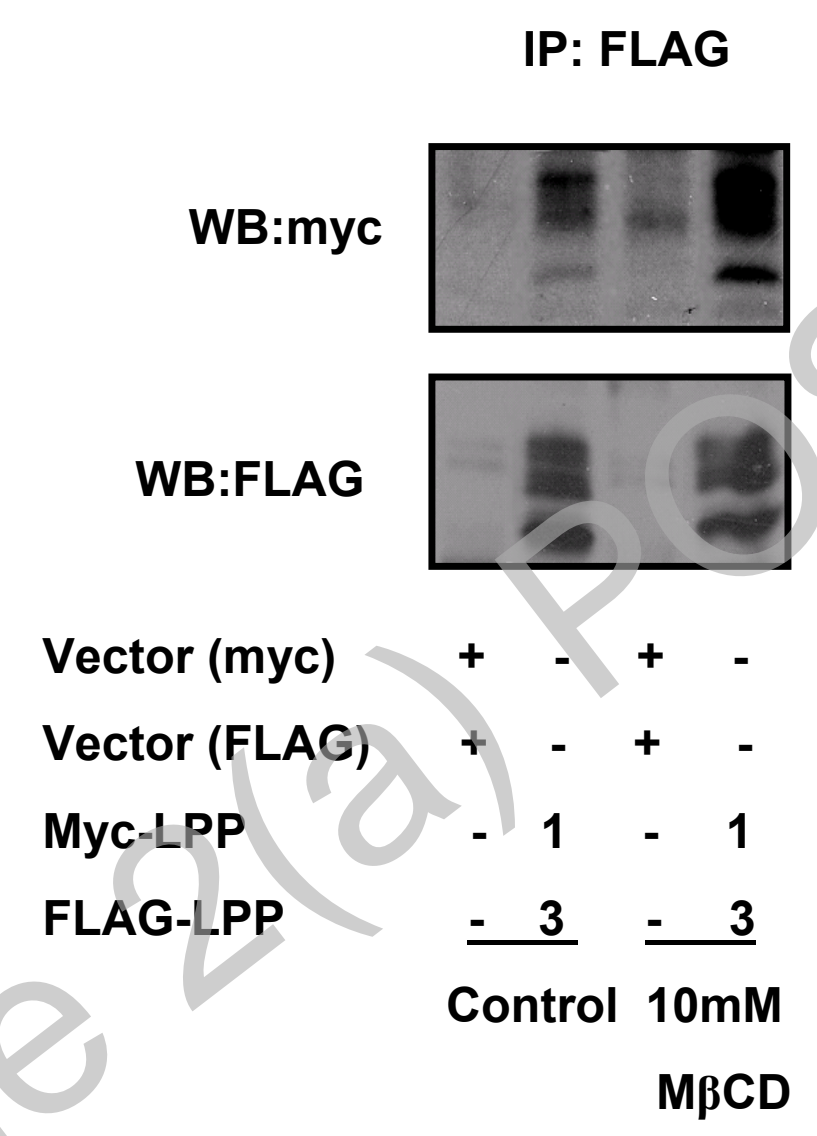




\section{B

Fig. 2

(a)

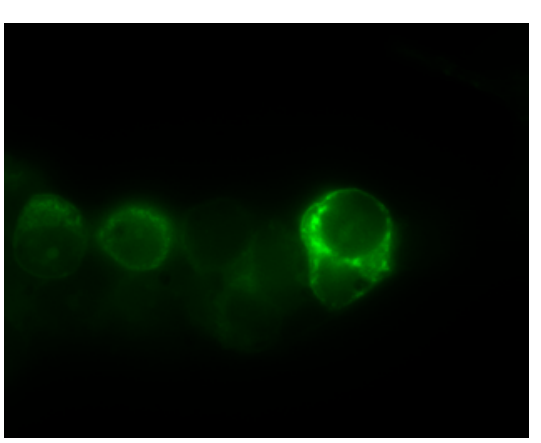

Myc-LPP1

(b)

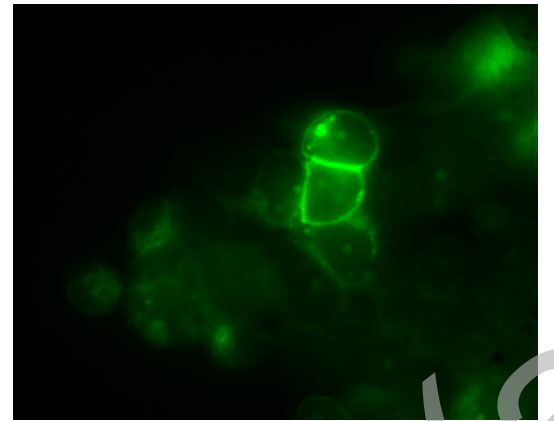

Myc-LPP3

1

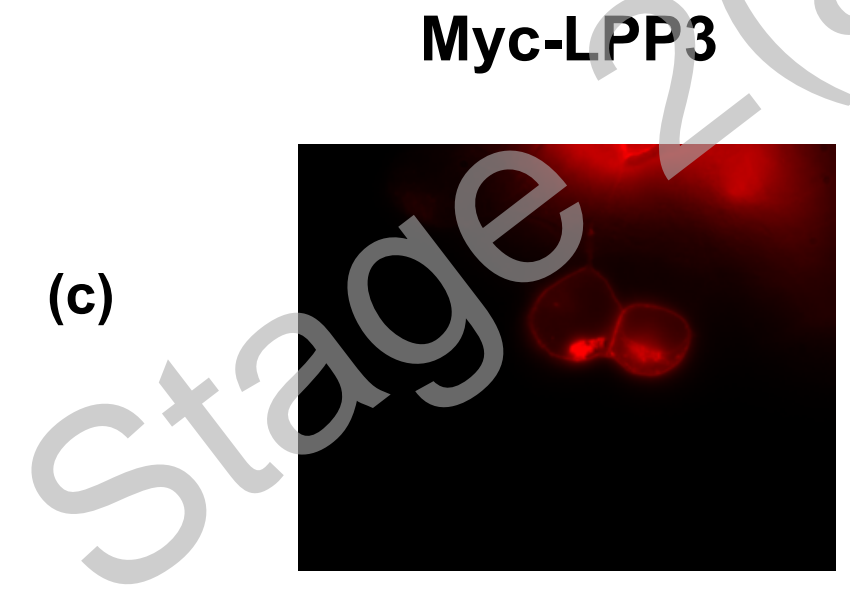

FLAG-LPP3
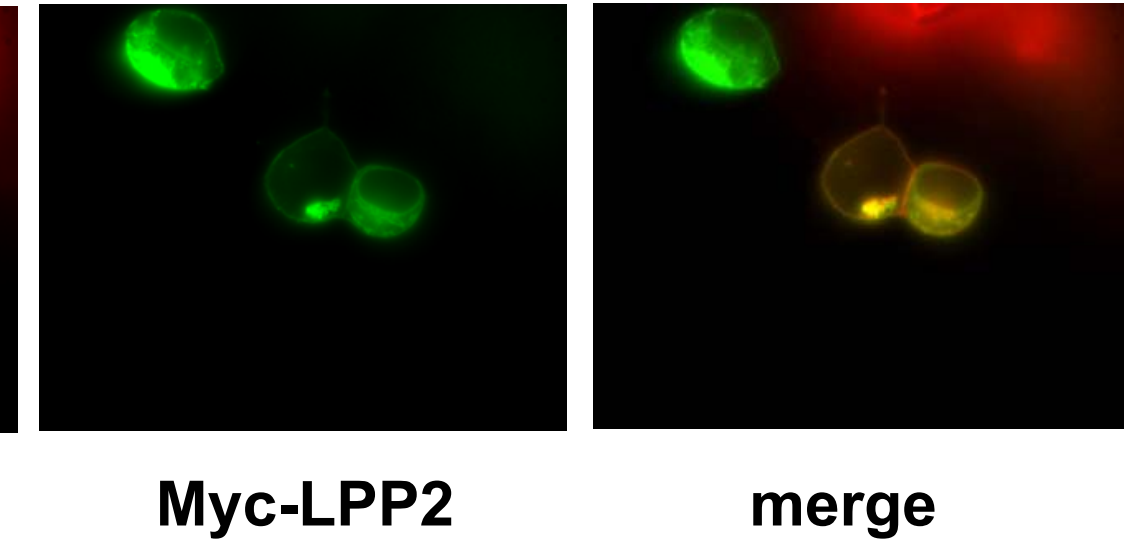

merge

Licenced copy. Copying is not permitted, except with prior permission and as allowed by law. 
Fig. 3a

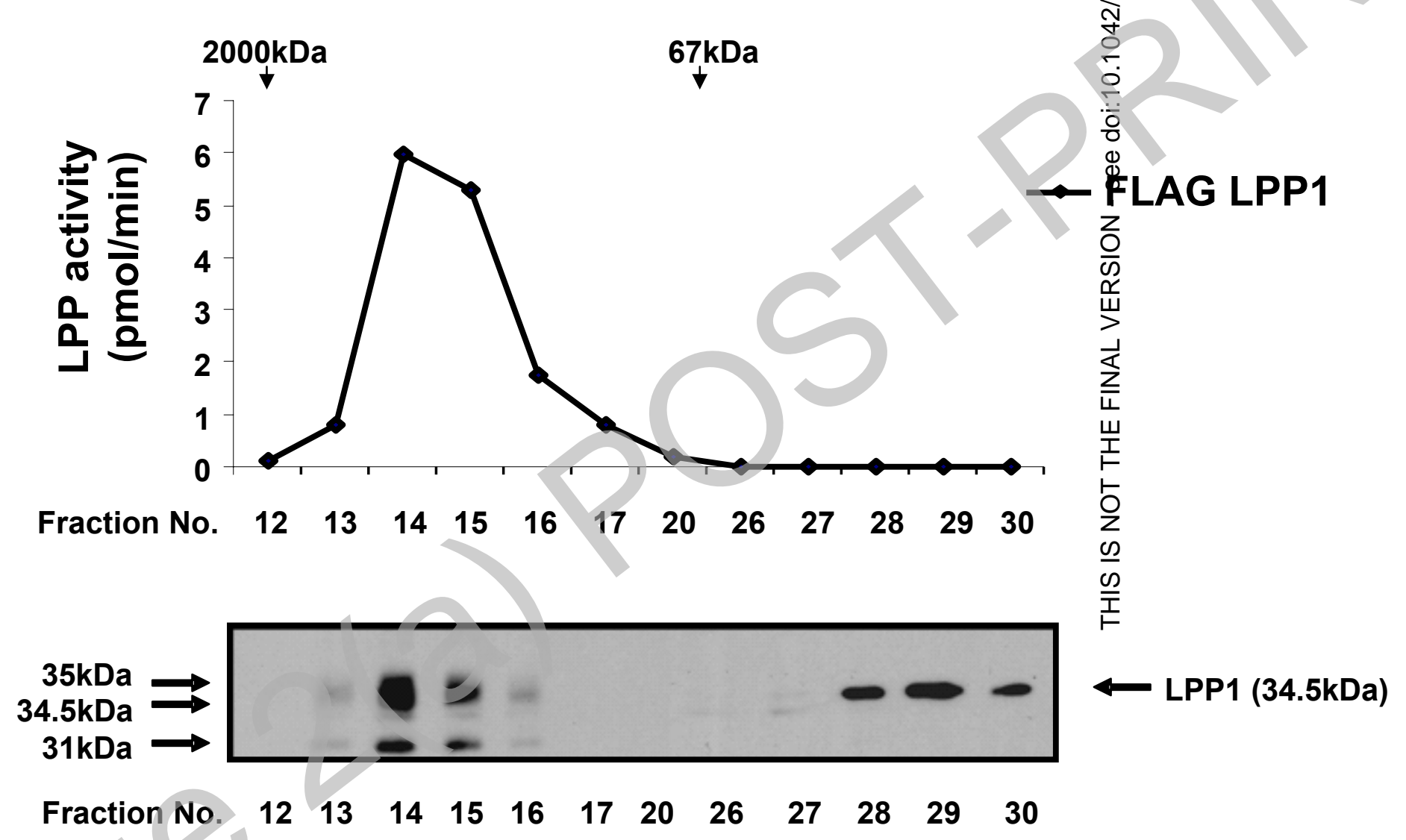


Fig. 3b

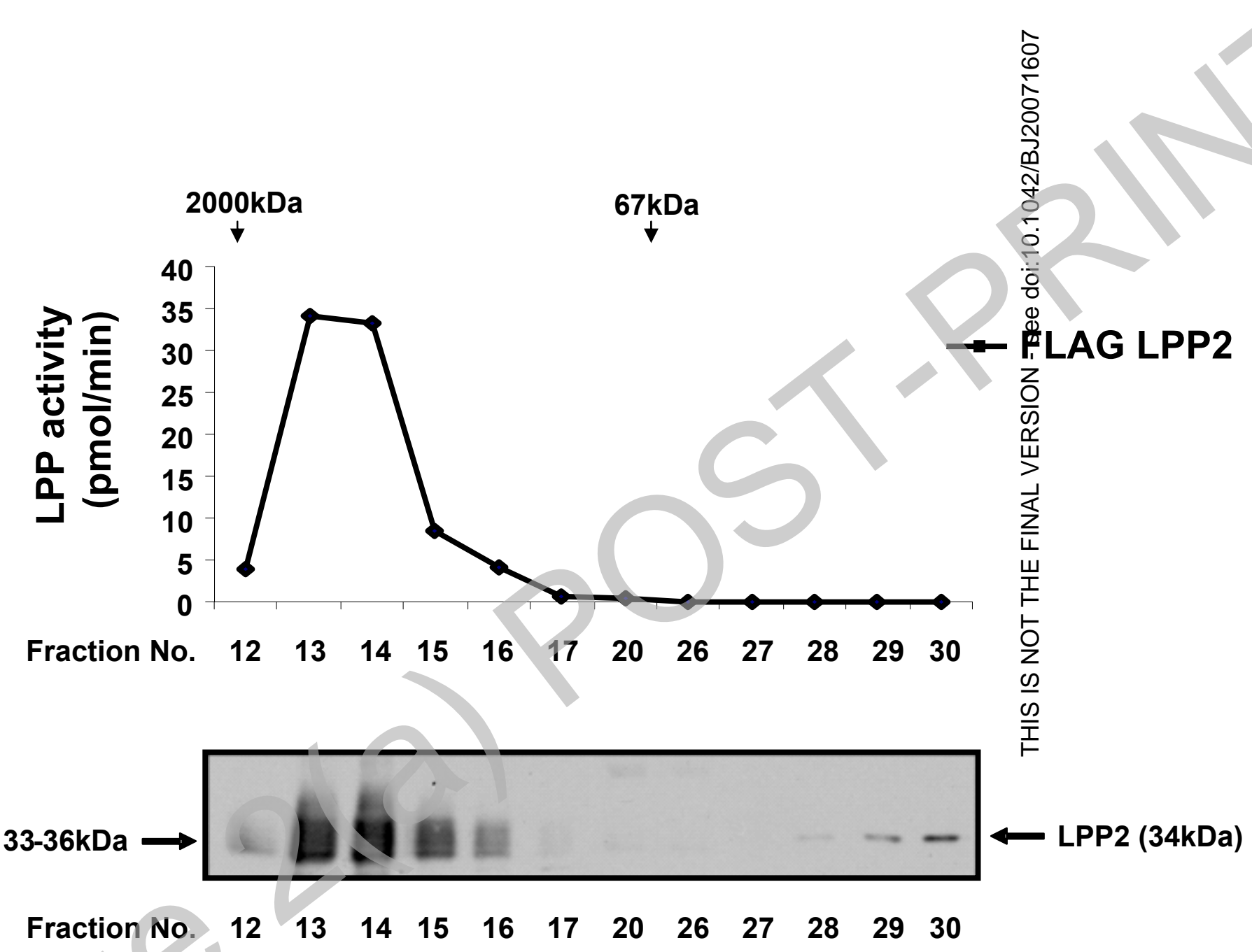


Fig. 3c

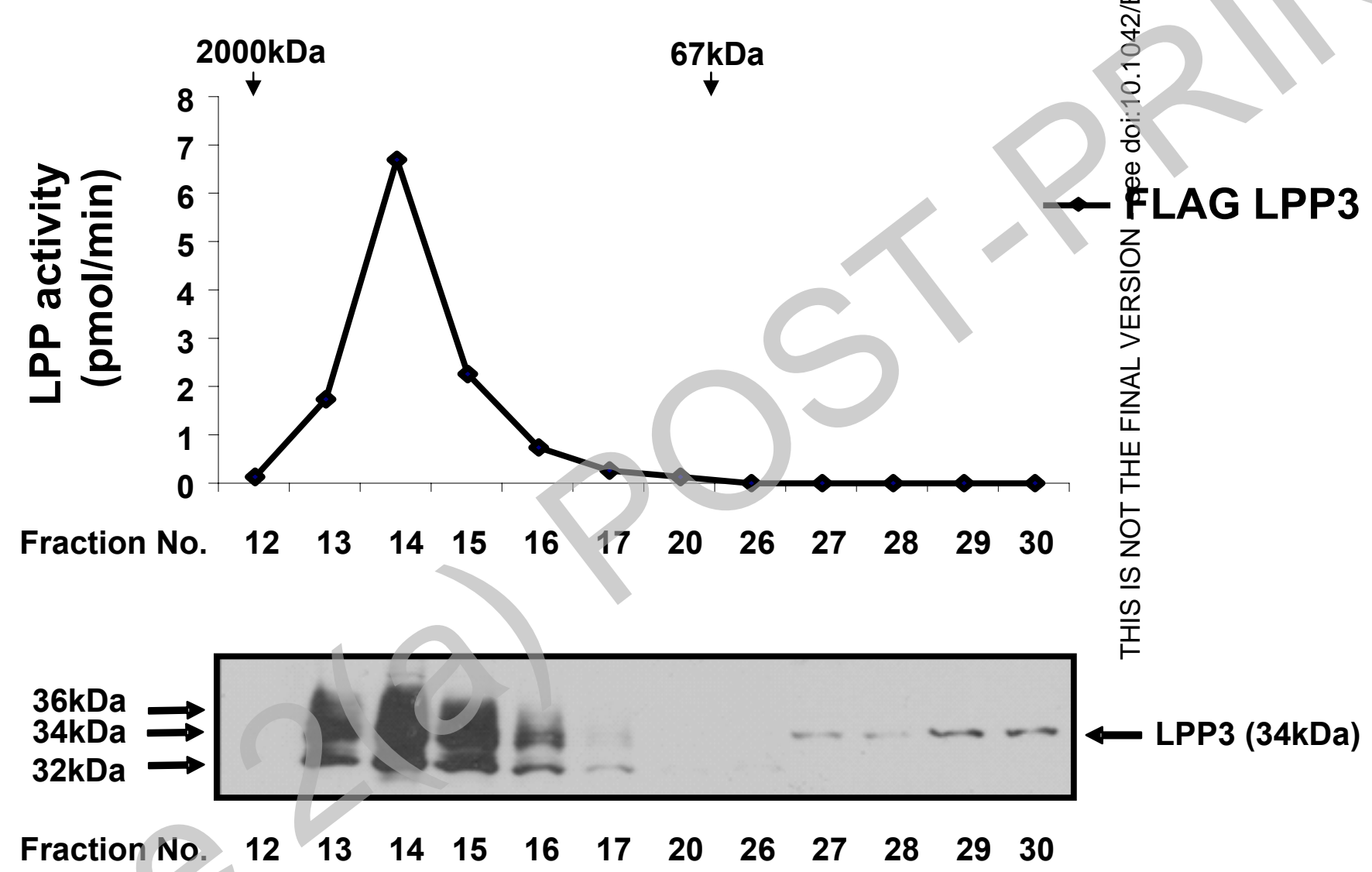


Fig. 3d

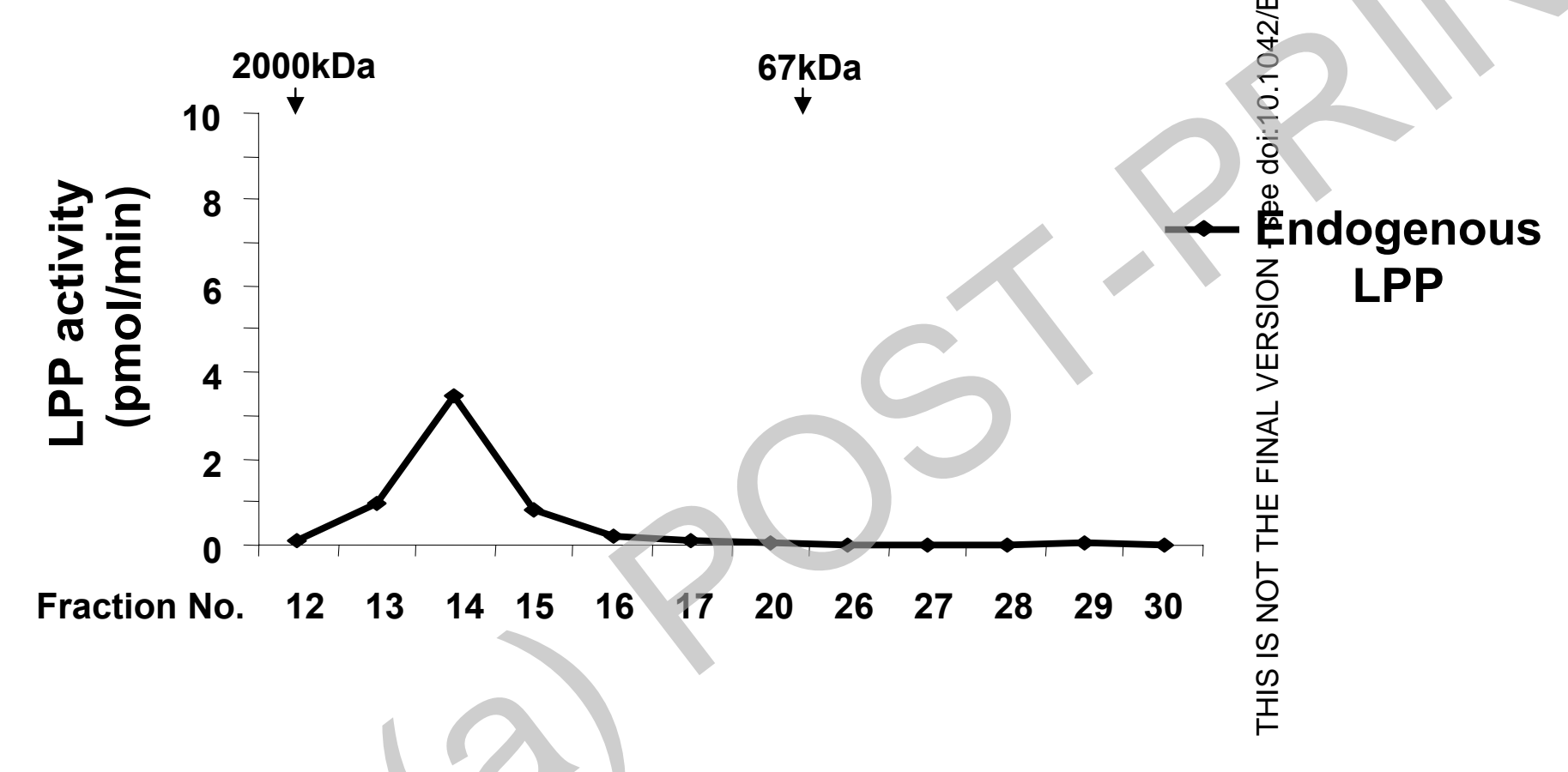

Licenced copy. Copying is not permitted, except with prior permission and as allowed by law.

(C) 2008 The Authors Journal compilation (c) 2008 Biochemical Society 
Fig. 3e

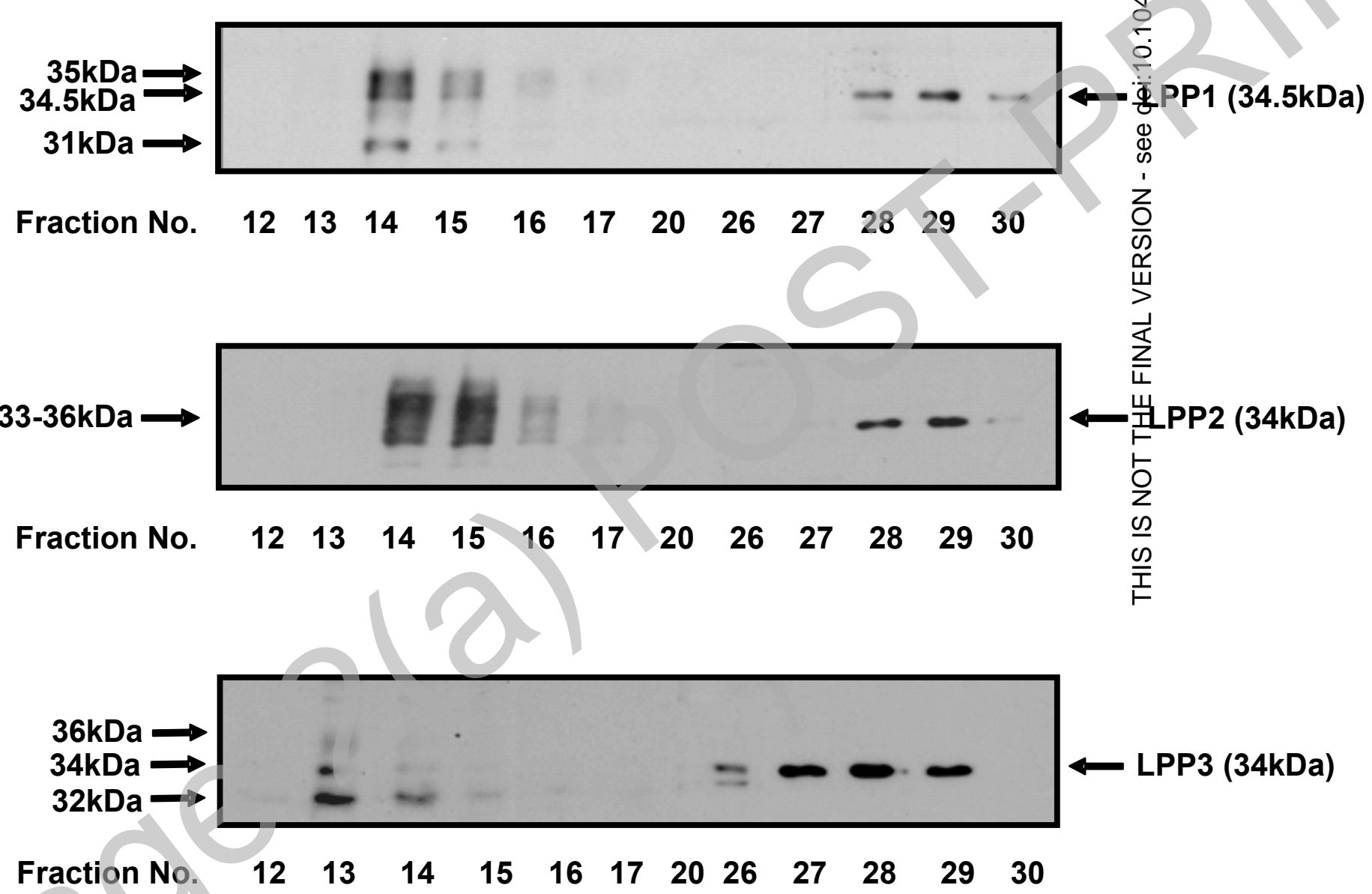




$$
\text { lis }
$$


Fig. 5

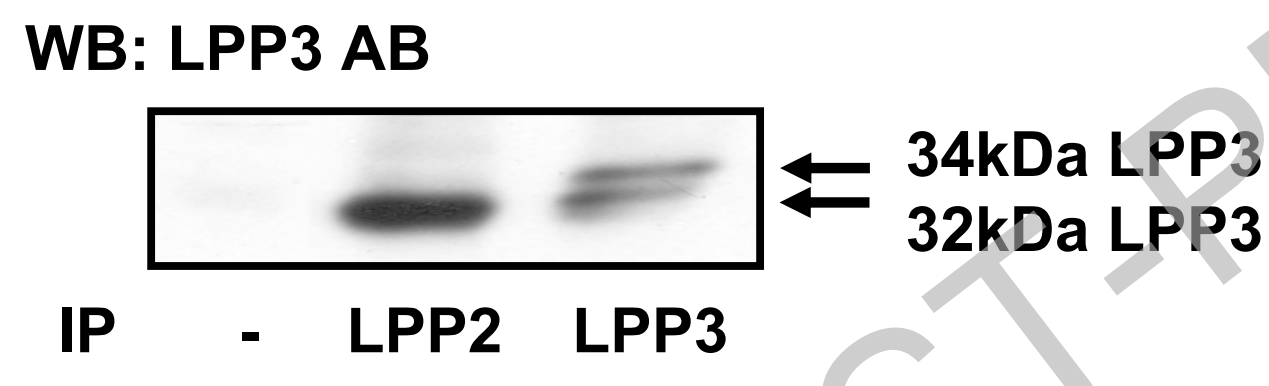

\section{WB: LPP2 AB}

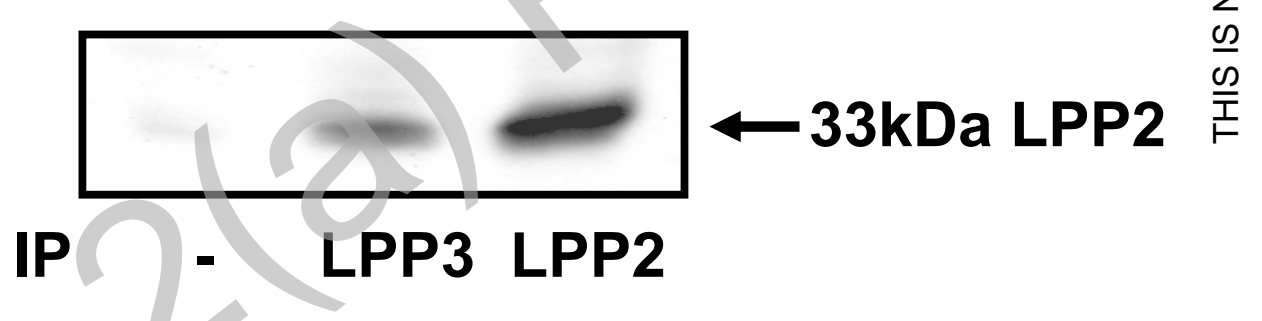

